\title{
Neurocognitive Functioning in AD/HD, Predominantly Inattentive and Combined Subtypes
}

\author{
Mary V. Solanto, Ph.D. ${ }^{1}$, Sharone N. Gilbert, Psy.D., Anu Raj, Psy.D., John Zhu, M.S.E.E. ${ }^{2}$, \\ Sabrina Pope-Boyd, Ph.D., Brenda Stepak, Psy.D. ${ }^{3}$, Lucia Vail, Ph.D. ${ }^{4}$, and Jeffrey H. \\ Newcorn, M.D. 1 \\ 1 Department of Psychiatry; The Mount Sinai School of Medicine; New York, N.Y. \\ 2Department of Psychology; Queens College; New York, N.Y. \\ 3Atlantic Rehabilitation Center; Morristown, New Jersey \\ 4Center for Intensive Treatment of Personality Disorders; St. Luke's- Roosevelt Hospital Center; New York, \\ N.Y.
}

\section{Abstract}

The Predominantly Inattentive (PI) and Combined (CB) subtypes of AD/HD differ in cognitive tempo, age of onset, gender ratio, and comorbidity, yet a differentiating endophenotype has not been identified. The aim of this study was to test rigorously diagnosed PI, CB, and typical children on measures selected for their potential to reveal hypothesized differences between the subtypes in specific neurocognitive systems (posterior vs. anterior attentional systems) and processes (arousal vs. activation). Thirty-four CB and 26 PI children meeting full DSM-IV criteria for subtype both in school and at home, without confounding reading disability or emotional disorder, were enrolled along with 20 typically developing children. Neurocognitive functions measured included attention, inhibitory control, working memory, learning, and executive functions. Tasks included the Stroop, Wisconsin Card Sorting Test, Continuous Performance Test (CPT), Buschke Selective Reminding Test, and the Tower of London (TOL), as well as instruments developed by Posner and Sternberg, and tasks assessing the impact on reaction time of varying preparatory intervals and stimulus/ response complexity. After co-varying for IQ, subtypes differed primarily on measures of impulsivity during tests of vigilance (CPT) and executive function (TOL), with the $\mathrm{CB}$ group showing greater impulsivity than both other groups. In addition, the PI group showed worse performance than CB and control groups on the WISC-III Processing Speed Index. Whether analyzed with or without an IQ co-variate, there was no support in the data for hypothesized differences between subtypes in functioning of the anterior vs. posterior attentional systems, nor in involvement of arousal vs. activation processes. The results indicate that the PI and CB subtypes are best differentiated by ratings, observations and tests of cognitive tempo and behavioral impulsivity. Neuropsychological methods have yet to identify critical neurobiological substrates of these differences.

The Predominantly Inattentive (PI) subtype of Attention-Deficit Hyperactivity Disorder (AD/ HD) was first delineated in the DSM-IV (American Psychiatric Association, 1994). Children with PI are impaired only in attention, whereas children with the more commonly recognized Combined (CB) subtype have impairments in both attention and hyperactivity-impulsivity. PI is more prevalent than CB in community-based studies (Gaub \& Carlson, 1997b; Gomez, Harvey, Quick, Scharer, \& Harris, 1999; Wolraich, Hannah, Pinnock, Baumgaertel, \& Brown,

Please send proofs to: Mary V. Solanto; Department of Psychiatry; The Mount Sinai School of Medicine; Box 1230, Gustave Levy Place; New York, N.Y. 10029-6574; Phone: 212-241-5420; Fax: 212-831-2871. 
1996), but constitutes only $30 \%$ of clinic-referred children with AD/HD (McBurnett et al., 1999), suggesting it may be under-recognized and under-treated.

Despite more than 20 years of research, relatively little is known about the neurobiology and etiology of PI. Indeed there is continuing controversy concerning whether it is truly a separate subtype of $\mathrm{AD} / \mathrm{HD}$, merely a variant in severity of $\mathrm{CB}$, or an entirely different disorder (Lahey, 2001; Milich, Balentine, \& Lynam, 2001). Phenotypic differences between PI and CB in age of onset, symptom profile, comorbidities, and social behavioral characteristics suggest differences in endophenotype that may in turn index underlying neurobiological differences (Castellanos \& Tannock, 2002).

Age of onset (Applegate et al., 1997) and referral (McBurnett et al., 1999) for PI are, on average, several years later than corresponding figures for $\mathrm{CB}$, which may reflect a different course of illness for the two conditions, and/or the likelihood that attentional demands reach a critical threshold later in a child's academic life than do expectations for behavioral self-control.

Children with PI are less likely to have oppositional defiant disorder (ODD) or conduct disorder (CD) (Eiraldi, Power, \& Nezu, 1997; Willcutt, Pennington, Chhabildas, Friedman, \& Alexander, 1999). Despite early indications that PI children are more anxious and/or depressed than those with CB (Lahey et al., 1988), recent studies reveal no differences between subtypes in internalizing symptoms, but rather find elevations in both compared to controls (Bauermeister et al., 2005; Power, Costigan, Eiraldi, \& Leff, 2004).

Whereas children with CB are typically described as 'always on the go", intrusive, and impatient, children with PI are more likely to be characterized as drowsy, sluggish and daydreamy, characteristics termed "sluggish cognitive tempo" (SCT). Parent and teacher ratings of SCT symptoms load onto a factor separate from other DSM-IV inattentive symptoms and are more likely to be elevated in PI compared to other subtypes (Hartman, Willcutt, Rhee, \& Pennington, 2004; McBurnett \& Pfiffner, 2001).

Socially, children with PI are more passive and less aggressive (Maedgen \& Carlson, 2000), less assertive (Pope, Solanto, Tryon, \& Stepak, 2005) and less knowledgeable of appropriate social behavior (Maedgen \& Carlson, 2000) than those with CB. Children with PI are more likely than typical children to be socially neglected whereas children with CB are more likely to be socially rejected (Maedgen \& Carlson, 2000).

\section{Implications of Subtype Differences}

Salient differences between PI and CB in behavioral, attentional, and social profiles suggest there are likely corresponding differences in underlying neurobiology which may be accessed by neuropsychological methods. It has been proposed that children with $\mathrm{CB}$ have a core deficit in inhibitory control such that they are unable (Barkley, 1997) or unwilling (Sonuga-Barke, Taylor, Sembi, \& Smith, 1992) to forego an immediate response to a stimulus in favor of a delayed, more adaptive response. Disinhibition, however, does not appear to characterize children with PI, who are more often described as sluggish, withdrawn, and hyporesponsive.

Differences between subtypes in cognitive tempo point to potentially important differences in the qualitative features of inattention, which suggest differences in etiology. Thus, whereas children with PI appear to be slow to orient and slow to respond to cognitive and social stimuli in their immediate surroundings, children with CB rapidly orient to novel external stimuli regardless of relevance. A series of studies in children who would now be classified as CB failed to identify deficits in the stimulus input stages of information-processing (Sergeant, 2005). The observably more sluggish orientation and response style of the child with PI by contrast, does suggest deficits in these early attentional processes. The current 
neuropsychological investigation of the PI and CB subtypes sought to assess the integrity of the brain regions and systems believed to underly these inhibitory and attentional processes.

Anterior vs. Posterior Attentional Systems-Functional differences between CB and PI subtypes may reflect differences in the relative functioning of the anterior and posterior attentional systems. The anterior attentional system (AAS), consisting of the anterior cingulate gyrus and the prefrontal cortex (PFC), mediates self-regulatory and executive functions, including inhibitory control, set shifting, working memory and planning (see for review Arnsten, 2001). In addition, the PFC has downward regulatory effects on subcortical regions, particularly the striatum which regulates motor output processes. In contrast, the posterior attentional system (PAS), comprised of the parietal cortex and structures in the midbrain and thalamus, mediates automatic perceptual processes, including visual orienting to novel stimuli (Posner \& Petersen, 1990). Children with CB not only display overt behavioral disinhibition, but they perform more poorly as a group than typical children on executive function tasks sensitive to the working integrity of the PFC and anterior cingulate (Nigg, 2005). Whereas a review of 13 studies of covert visuospatial orienting found no consistent evidence of PAS dysfunction in children with CB (Huang-Pollock \& Nigg, 2003), the attentional characteristics of PI children $d o$ suggest they have a deficit in automatic attentional processes mediated by PAS.

Arousal vs. Activation-Among neural mechanisms which subserve cognition, another distinction is that between an arousal system, which mediates perceptual input processes, and an activation system, which facilitates motor preparedness and motor output processes (Tucker $\&$ Williamson, 1984). Sanders (1983) distinguished the task variables such as signal intensity and novelty, that influence the arousal system from those, such as warning or preparatory interval, that affect the activation system.

These concepts were recapitulated and developed in Sergeant's "cognitive-energetic" model (Sergeant, 2005), which posits the existence of "arousal" and "activation" pools that mediate stimulus input and response output processes, respectively. Both pools are maintained and modulated by an overarching "effort" pool. Deficits in motor readiness, response organization, and response monitoring in children with CB implicate the activation system (Sergeant, 2005). Clinical observations of children with PI, on the other hand, suggest they have deficits in orienting and habituation, implicating the arousal system. Slower speed of processing in the PI subtype also points to differences between subtypes in energetic factors.

Integration and Hypotheses-Integration of these theoretical considerations with the behavioral phenomenology of the PI and CB subtypes leads us to the following hypotheses:

(1) Behavioral disinhibition, as well as the presence of executive dysfunction in CB suggest primary involvement of the AAS. The unfocused, lethargic attentional style of the PI subgroup, on the other hand, in the absence of disinhibition, points to greater involvement of the PAS. We test this hypothesis using a battery of tasks shown to be sensitive to the functioning of brain regions within these two attentional systems. We predicted greater deficits in CB than PI on a measure of motor inhibition (Conners= Continuous Performance Test), a measure of aversion to delay (Sonuga-Barke, Taylor, Sembi, \& Smith, 1992) shown to have ecological validity as a measure of impulse control (Solanto et al., 2001). Also predicted was worse performance by CB on a measure of cognitive inhibitory control (Stroop) shown to activate the anterior cingulate (Bush et al., 1998). Furthermore, we predicted that children with CB would perform worse than PI on the Wisconsin Card Sorting Task (WCST), a measure of cognitive set-shifting, and also on the Tower of London (TOL), a measure of 
spatial working memory, both of which have been associated with activation of the dorsolateral PFC (Baker et al., 1996; Berman et al., 1995).

(2) The slower cognitive tempo of the PI subgroup suggests that the PAS, which mediates automatic orienting to novel stimuli may be dysfunctional in PI. We therefore predicted that compared to children with $\mathrm{CB}$, children with PI would show greater "costs" in slowed reaction time (RT) to an invalid cue on the "Posner" task of covert visuospatial orienting (Posner \& Petersen, 1990), which was designed to assess the functional integrity of the AAS and PAS.

(3) We posited greater involvement of the arousal (stimulus input) system in children with PI and greater involvement of the activation (response output) system in children with CB. On the Sternberg short-term memory task, an increase in memory load was expected to differentially slow the performance of children with PI compared to those with CB. Similarly, increased difficulty processing a stimulus would differentially impair the performance of children with PI compared to those with CB or typical comparison (TC) children. In contrast, increased difficulty of the response would differentially impair performance of children with CB. Thirdly, we predicted that a shorter preparatory interval on a warned reaction time task would tax stimulus orientation (arousal) processes (as predicted by Sanders) whereas a longer warning interval would test maintenance of motor readiness (activation) processes. Thus, according to our hypotheses, children with PI would perform better with longer preparatory intervals, whereas children with CB would perform better with shorter intervals.

(4) Finally, given hypotheses of memory search and retrieval deficits in PI as well as early research suggesting a memory retrieval deficit in children with Attention Deficit Disorder without Hyperactivity (DSM-III) (Barkley, DuPaul, \& McMurray, 1991), tests of verbal (Buschke) and visuospatial (Visual Learning Test) memory were included in the battery.

Prior Subtype Comparison Studies-Previous studies have been inconsistent with respect to subtype differences in executive functions. Some studies have found differences in perseverative errors or categories completed on the WCST (Houghton et al., 1999), whereas others have not (Klorman et al., 1999; Geurts, Verte, Oosterlaan, Roeyers, \& Sergeant, 2004). Similarly, children with CB had lower performance scores than children with PI or typical children on the TOL or similar Tower of Hanoi in two studies (Klorman et al., 1999; Nigg, Blaskey, Huang-Pollock \& Rappley, 2002), but not in another (Houghton et al., 1999). Subtypes were compared in two previous studies employing the Conners' CPT: In a study with girls, CB exceeded PI with respect to errors of commission and exceeded comparisons with respect to errors of omission (Hinshaw et al., 2002) whereas a more recent study failed to find any differences at all between either AD/HD subtype and normal comparisons (Bauermeister et al., 2005).

The study to be described differed from prior neurocognitive research in that it incorporated all of the following methodological refinements in order to reduce heterogeneity within subtype and thereby enhance the likelihood of identifying endophenotypic differences between groups:

(1) Given indications of differences in severity of AD/HD symptoms between genders (Gaub \& Carlson, 1997a; Gomez et al., 1999) and across age groups (Pelham, Gnagy, Greenslade, \& Milich, 1992), entry criteria on rating scales were specified in terms of T-score thresholds on ratings on age-and gender-normed questionnaires, rather than simple symptom counts on DSM-IV-based checklists; 
(2) Given indications that ratings by parents and teachers separately identify different groups of children (Gomez et al., 1999; Schachar, Tannock, Marriott, \& Logan, 1995) eligibility criteria for the current study required concordance by parent and teacher on presence/absence of inattentiveness and hyperactivity-impulsivity.

(3) Finally, given the possibility that subtle but systematic differences between subtypes in learning processes could easily affect neurocognitive test results, reading and language disorders were exclusionary for all participants.

\section{Method}

The study received the approval of the Institutional Review Board at Mount Sinai.

\section{Overview of Procedures}

Eligibility was assessed in four stages: (1) a phone screen (2) completion of questionnaires by parents and teachers (3) face-to-face diagnostic interviews of parent and child and (4) intellectual and achievement testing. Eligible children subsequently received the full battery of neurocognitive tests, administered over two 2.5 -hour test sessions.

\section{Recruitment}

Children with attention problems were recruited via notices placed on websites of lay selfadvocacy groups (eg. CHADD), circulated to pediatricians and schools, placed in local newsletters and posted on bulletin boards within the medical center. Children without attention problems were recruited in a similar manner, excepting publicity to lay advocacy groups.

\section{Selection Criteria}

Inclusion-The following inclusion criteria were utilized to ensure that children could be unambiguously assigned to one of the two $\mathrm{AD} / \mathrm{HD}$ groups or to the TC group:

(1) Age between 7 and 12 years of age; (2) Concordant parent and teacher reports on the Conners Parent Rating Scale (long form) (CPRS) (Conners, Sitarenios, Parker, \& Epstein, 1998b) and Conners Teacher Rating Scale (CTRS) (long form) (Conners, Sitarenios, Parker, \& Epstein, 1998a), as follows for each group. Combined: T-scores $\geq 65$ on both the DSM-IV Inattentive and DSM-IV Hyperactive-Impulsive Scales; Predominantly Inattentive: T-scores $\geq 65$ on the DSM-IV Inattentive Scale and $<65$ on the DSM-IV Hyperactive-Impulsive scale; (3) Diagnosis of AD/HD, CB or PI subtype on the basis of the DISC-IV structured diagnostic interview of the parent. Absence of any diagnosis for the TC group; (4) Expert clinical diagnosis of $\mathrm{AD} / \mathrm{HD}$, based on a review of all information collected.

Children in the TC group had no attention, learning, emotional, or behavioral problems as assessed by the clinical and structured interviews with the parent and the child and the narrative on the Teacher Report Form. Children in the TC group had scores within 1 SD of the mean (Tscore $\leq 60)$ for age and gender on the CPRS and CTRS DSM-IV Inattentive and DSM-IV Hyperactive-Impulsive scales.

Exclusion-Children currently receiving any psychotropic medication were excluded. In addition, the following exclusion criteria were applied to all groups.

(1) WISC-III Full Scale IQ <80; (2) (WISC-III Verbal IQ-Performance IQ split > 23) and (VIQ or PIQ < 100). The criterion for VIQ-PIQ difference was applied to ensure the exclusion of children with extreme differences in processing between verbal and non-verbal domains, even in the absence of an overt learning disability. A 23-point difference between VIQ and PIQ represents the difference which occurred less than $5 \%$ of the time in the normative sample of 
7-year olds (Wechsler, 1991). (3) Reading Disability, as indicated by either of the following: Significant difference between the predicted and actual standard scores on the Reading Composite score on the Wechsler Individual Achievement Test (WIAT), or a Reading Composite standard score less than or equal to 85; (4) Pervasive Developmental Disorder, assessed on the basis of the clinical interviews and the developmental history; (5) Developmental Language Disorder, screened using the Boston Naming Task and the Tests of Language Competence - Expanded Edition (TLC-E); (6) Presence of any of the following psychiatric conditions: Mood disorder, Tourette Syndrome, Psychotic Disorder, established on the basis of the DISC-IV interview and corroborated by results of the open-ended clinical interview. Comorbid externalizing disorders were not exclusionary; (7) Chronic medical or neurological condition or sensory handicap; (8) Color-blindness, because many of the tests in the neurocognitive battery have colored stimuli. Color blindness was assessed using the Ishihara plates (Ishihara, 1960).

\section{Phone Screen and Questionnaires}

A phone screen was conducted to ascertain whether children were within the appropriate age range, free of psychotropic medication, had no apparent learning, emotional, or chronic medical or neurological conditions, spoke English as a first language, and had at least 5 of the 9 DSMIV inattentive cluster of symptoms. The following questionnaires were sent to families with children who met the screening criteria: CPRS, CTRS, Child Behavior Checklist (CBCL) and corresponding Teacher Rating Form (TRF), SNAP-IV Parent/Teacher Rating Scales of DSMIV symptoms of AD/HD and ODD, and the Social Skills Rating Scale, Parent and Teacher forms. A consent form was included for parents to sign and give to teachers. Parents and teachers separately returned their packets by mail directly to the investigators. To ensure independence of cases, only one child per family was included.

\section{Evaluation (Sessions One and Two)}

Parents gave informed signed consent to participate and children signed an assent following a description in language understandable to them. The unstructured interview of the parent(s) comprised a comprehensive review of the child's current symptoms, developmental history, behavioral, social and emotional history and current functioning, as well as the family psychiatric history, family cohesiveness, and disciplinary style. A semi-structured interview of the child (available upon request to the first author) allowed for direct observation and clinical assessment of emotional, social, and behavioral functioning, as well as identification of possible sources of stress, distress, or conflict in the child's home or school environment. These clinical interviews were necessary to ascertain DSM-IV Criterion E for AD/HD "that symptoms are not better accounted for by another mental disorder."

The DISC-IV structured diagnostic interview of the parent (Shaffer et al., 1996) and the testing of the child were conducted by a Ph.D. psychologist or a Master's level doctoral student who were fully trained in the procedures. The same professional who administered the WISC-III and WIAT also administered the neurocognitive tests to a given child in order to maximize comfort and consistency. Examiners were not blind to the child's group membership.

The following WIAT subtests were administered: Basic Reading (word recognition), Reading Comprehension, Mathematics Reasoning, and Numerical Operations (computation). An agebased Reading Composite score was generated from the Basic Reading and Reading Comprehension subtest scores. An age-adjusted regression formula utilizing the WIAT normative data tables (Wechsler, 1992) was used to predict the Reading Composite score from the child's WISC-III Full Scale IQ score. A difference between the predicted and actual agebased Reading Composite scores occurring at a chance frequency less than .05 was the criterion for diagnosis of a reading disability. Although age-based WIAT scores were used to identify 
and exclude children with a reading disability because the formula requires the WISC and WIAT scores to be in the same metric, grade-based WIAT scores have greater clinical utility and were used to compare the subgroups on academic functioning.

The Boston Naming Test (Kaplan, Goodglass, \& Weintraub, 1983) and two subtests of the TLC-E (Wig \& Secord, 1989) were used to screen for developmental language disorders. The TLC-E subtests assess higher order language functions, specifically Making Inferences (subtest 2) and Figurative Language (subtest 4). These tests were selected because test stimuli are presented simultaneously in the auditory and visual modalities, minimizing confounding demands on attention.

Parents completed the Child Depression Inventory (CDI) (parent form), and completed as well the Multidimensional Anxiety Scale for Children (MASC) as they believed the child would respond. At the close of the semi-structured interview, the CDI (Kovacs, 1992) and MASC (March, Parker, Sullivan, Sullivan, Stallings, \& Conners, 1997) were administered orally to the child to ascertain whether the PI and CB groups differed in internalizing symptomatology even after exclusion of diagnosable conditions. In that instance, scores on these scales were to be entered as co-variates in the analyses.

\section{Neurocognitive Testing}

Sessions Three and Four-Testing was conducted in the morning in order to avoid effects of stress or fatigue. Parents were asked to ensure that children had adequate sleep the night before and adequate nutrition on the morning of testing. Tests were presented in a fixed order on each day. In order to maintain the child's interest and cooperation, tests alternated between those presented in the verbal and visual modalities and also between those administered on the computer and those which utilized manipulanda.

\section{Instruments}

Computerized tasks were presented on a desk-top computer with a 15" color monitor. The Sternberg and Posner tasks were programmed and presented using the Micro Experimental Laboratory (MEL) system (Schneider, 1990). Details not presented here concerning the tasks are available from the first author.

Delay Aversion Test (DAT)—The Delay Aversion Paradigm (Sonuga-Barke et al., 1992) conceptualizes impulsive behavior as a choice to avoid delay, which the individual with ADHD finds aversive. The version of the DAT used in this study is identical to the "Change-Delay Task," used in a previous study (Solanto et al., 2001). Since the previous results showed that the first of two blocks best differentiated the ADHD and TC groups, one block of 20 trials was presented in the current study. Left or right side of presentation of the large reward was counterbalanced within participants' handedness. Aversion to delay, predicted to be greater in $\mathrm{CB}$, was indexed by the percentage of trials on which the larger, delayed reward was selected.

Bushke Selective Reminding Test-This list-learning task allows for measurement of encoding and short-and long-term storage and retrieval processes (Buschke \& Fuld, 1974). The 12-item list was administered and scored as per Spreen and Strauss (1998). We predicted worse performance by the CB group on the four main outcome measures: Total Recall, Long-term Storage, Long-term Retrieval, and Delayed (30 min) Recall.

Visual Learning Test of the WRAML (VLT)-This is a test of memory of spatial location of 9 or 14 designs (depending on age) on a grid board (Sheslow \& Adams, 1990). We predicted that the age-based standard score would be lower in the CB group than the other groups. 
Sternberg Task-This visual memory search task (Sternberg, 1969) has been used in numerous studies within the context of the Additive Factors Method to assess deficits in the search and decision stages of information-processing (Sergeant \& Scholten, 1983). The subject must ascertain whether a stimulus (letter or number) contained in a "memory set" is present in a subsequently presented "response set." Response time is an index of memory search rate and increases linearly with information load (Sergeant \& Scholten, 1983).

The memory set consisted of 1 or 4 items, with duration of $1 \mathrm{sec}$ or $4 \mathrm{sec}$, respectively, and was followed immediately by the response set. Response sets consisted of 16 items displayed for $4 \mathrm{sec}$ in a $4 \times 4$ matrix. Forty trials were presented, of which $50 \%$, in random order, contained an item from one of the two memory sets.

Stroop Color-Word Test-The paper version of this test was administered and scored using the original procedures of Golden (1978). The Interference score was converted to a T-score such that a higher score indicated better performance. Worse performance was predicted for CB compared to both other groups.

Conners $=$ Continuous Performance Test - On the Conners $=$ CPT (Conners, 1994) targets occur frequently, creating a positive set to respond. The subject must withhold a response to infrequently occurring (25\%) non-targets. Thus, this task is theoretically more sensitive to inhibitory control than traditional CPTs. The task consists of 360 trials, presented in six blocks each comprised of 20 trials at each of three inter-stimulus intervals $(1,2$ and 4 sec) in counterbalanced order.

We predicted: (a) commission errors, indexing inhibitory control, would be greater for the $\mathrm{CB}$ than PI and TC groups; (b) Beta would be lower (indicating greater risk-taking) in CB than PI or TC; (c) increases in inter-stimulus interval (ISI) would have a greater deleterious effect on slope of RT over time (RT-ISI change) in the CB group than either the PI or TC group because of the greater deficits in $\mathrm{CB}$ in motor activation; (d) given their slower cognitive tempo, RT to hits (Hit RT) would be slower in PI, but more variable (Hit RT SE) in CB; (e) the index of Attentiveness ( $\mathrm{d} \mathrm{N}$ ) would be worse in both AD/HD groups than in TC.

During CPT administration, the examiner was seated outside of the child's field of vision and rated the child's behavior on a 10-item checklist of off-task behaviors, that was found previously to be sensitive to the effects of methylphenidate (Solanto, Wender, \& Bartell, 1997). Each item was scored with respect to the actual number of occurrences, and rated from 0 to 3 on a scale of severity. Scores were summed over the ten items.

Posner Test-The Posner is a covert visuospatial orienting task designed to assess the functional integrity of three attentional networks: AAS, PAS and the tonic/phasic arousal system (Posner \& Petersen, 1990). The target stimulus is preceded by a cue, which may be valid, invalid, double, or null. A valid cue is expected to provide "benefits" in the form of reduced RT whereas an invalid cue exacts "costs" in RT because it requires disengagement, shifting, and re-engagement of attention to the correct location. Lesions of the posterior parietal cortex result in disproportionately increased RT following an invalid cue (Posner \& Raichle, 1994).

The display consisted of a two rectangular boxes located $5 \mathrm{E}$ to the left and right of a central fixation point (plus sign). The (exogenous) cue was a "brightening" of the box (created by the appearance of a second box around the first) which preceded the appearance of the target (an asterisk) in the box. On $67 \%$ of all trials the cue was valid - i.e. appeared around the box in which the target subsequently appeared. On $11 \%$ of trials respectively, the cue was invalid (opposite box), double (both boxes), or null (neither box). Cue types were presented in random 
order. The interval between cue onset and target onset was randomly varied between $200 \mathrm{msec}$ (50\%) and $800 \mathrm{msec}$. Five blocks of 72 trials were presented. A head rest positioned the child's head at a centered distance of $40 \mathrm{~cm}$ from the monitor.

To ensure that each response represented a true response to the stimulus, only (accurate) responses occurring between $150 \mathrm{msec}$ and $1000 \mathrm{msec}$ after target onset were analyzed. We hypothesized that an invalid cue would cause a larger increase in RT in the PI compared to the $\mathrm{CB}$ and TC groups which would not differ from each other. Also predicted was a main effect of Group on RT such that the PI group would be slower than both the CB and TC groups.

Tower of London (TOL) - The TOL was administered using the standard apparatus and instructions (Culbertson \& Zillmer, 2001). We predicted worse performance on the TOL in the CB than other groups with respect to Total Moves required to complete the items, as well as Rule Violations, an index of impulse control on this task. Longer Total Execution time in PI was predicted, given more sluggish cognitive tempo.

Stimulus-Response Processing Task (SRPT)—This target detection task, developed in our laboratory, systematically varies the difficulty of the stimulus and the difficulty of the response. The target stimulus was a white " $X$ " (25 mm wide X $28 \mathrm{~mm}$ high) presented in one of four different horizontal positions within a larger black rectangle. In the "easy" stimulus condition, the positions to the right and left of the target " $X$ " were blank. In the "hard" stimulus condition, the " $X$ " was flanked by three star-like figures with the same overall dimensions, each created by the intersection of six lines. In the "easy" response condition, the child simply pressed the "green" key labeled "YES" if the target was present and press the "red" key labeled "NO" if it was absent. In the "hard" response condition, the child pressed one of four keys corresponding to the position where the target appeared. A fixation pattern was presented for $500 \mathrm{msec}$, followed by a $500 \mathrm{msec}$ offset interval, followed by the target. The task was presented in two sequences, each consisting of one trial block of each of the four possible easy-hard, target-response combinations. The order of the four blocks within each sequence was randomly determined at the outset of the study and then fixed for all presentations. Each block consisted of 25 trials and 5 "catch" trials in which no target appeared. Increased difficulty of the stimulus was predicted to differentially increase RT of PI, whereas response difficulty was predicted to differentially increase RT of CB.

Wisconsin Card Sorting Test.(WCST)-This test measures the ability to form, maintain, and shift cognitive set and to inhibit a prepotent response (Berg, 1948). The test was administered using the original card decks and scored using procedures described by Heaton (1981). We predicted that the CB group would require more trials to achieve the first category, would have more failures to maintain set, would achieve fewer categories, and would make more perseverative errors and more errors overall.

Warned Simple Reaction Time Test (WSRT)—This task, developed in our laboratory, required a response as quickly as possible to an imperative stimulus that was preceded at varying intervals by a warning stimulus. The imperative stimulus was a red rectangle ( 22.5 $\mathrm{mm}$ wide X $25 \mathrm{~mm}$ in high). The warning stimulus (an asterisk in 26-point font) appeared in the center of the black rectangle at one of three different intervals (1000, 4000, and $8000 \mathrm{msec})$ before onset of the imperative stimulus. Twenty trials at each of the three warning intervals were presented in random order. It was predicted that RT for PI would be slowest at the shortest preparatory intervals, whereas RT for CB would be slowest at the longest intervals. 


\section{Data Analysis}

Results were analyzed using SPSS (Version 13) software. Separate MANOVAs/MANCOVAs were performed for each test yielding multiple scores. Multivariate F-values reported are Wilks' Lambda. For each test having only one performance measure of interest, an ANOVA/ ANCOVA was performed. Post-hoc pair-wise comparisons of significant results were conducted using the method of least significant differences (LSD). Categorical variables were analyzed by chi-square. Given significant differences in IQ between groups and disagreement over whether such differences ought to be co-varied (Lahey et al., 1998; Werry, Elkind, \& Reeves, 1987), all neurocognitive data were analyzed both with and without an IQ co-variate.

\section{Results}

Of parents of 604 children screened by phone as described above, 237 (39\%) passed screening criteria and were mailed packets. Of these, 134 children met Conners criteria for the CB group $(n=55)$, the PI group $(n=36)$ or the TC group $(n=43)$. Twenty of these children had strong indicators in the questionnaires of a learning disorder and/or a comorbid psychiatric condition and were eliminated from further consideration. After evaluation, thirty-four of the remaining 114 were excluded from continued participation due to one or more of the following: not diagnosed with $\mathrm{AD} / \mathrm{HD}(\mathrm{n}=4)$; referred for the TC group but found to have a psychiatric condition $(n=4)$; FSIQ < $80(n=4)$; Verbal-Performance IQ split $>23(n=3)$; reading disability $(\mathrm{n}=9)$; language-based learning disability $(\mathrm{n}=5)$; comorbid anxiety disorder $(\mathrm{n}=2)$; comorbid depressive disorder $(\mathrm{n}=1)$; failure to complete the evaluation $(\mathrm{n}=1)$; eligible, but declined to continue $(\mathrm{n}=2)$. The remaining 80 children, in the following groups, constituted the final sample: PI subtype of $\mathrm{AD} / \mathrm{HD}(\mathrm{n}=26)$; CB subtype of $\mathrm{AD} / \mathrm{HD}(\mathrm{n}=34)$; TC $(\mathrm{n}=20)$.

A combined sample of 80 children in three groups analyzed via one-way ANOVA provides power of .80 to detect an effect size of .35, which is small to medium (Cohen, 1988).

\section{Sample Characteristics (Table 1)}

The sample was diverse with respect to socio-economic characteristics, with broad representation of lower, middle, and upper income levels. Public assistance was the primary means of support for $3.8 \%$ of families. Differences between groups in gender distribution, age, and minority status were not significant. ANOVA revealed that both $\mathrm{AD} / \mathrm{HD}$ groups had lower WISC-III Full Scale IQ than the TC group but did not differ significantly from each other. Mothers and fathers of children in the TC group had achieved higher educational levels than those in the PI group, who, in turn, were better educated than those in the CB group; however, these differences did not reach significance by chi-square.

Only one of the children in the AD/HD groups had received a prior evaluation and diagnosis of AD/HD; all others were newly presenting for evaluation. This child was tested at the end of the summer, during which he had not received any medication. All other children were medication-naive with respect to all psychotropic drugs.

Children were classified as having SCT if the teacher endorsed Item 19 ("stares into space and reports daydreaming") as well as Item 20 ("appears to be low in energy level, sluggish, or drowsy") on the SNAP-IV. Thirteen children (50\%) in the PI group received ratings of at least 2 ("very much") on both of these items and were designated as having SCT. By contrast, only 2 (5.9\%) of those in the CB group and none in the TC group were similarly rated. The difference across groups was highly significant: $\chi(2,80)=24.98, \mathrm{p}=.000$. Post-hoc chi squares showed that the PI group significantly exceeded both the $\mathrm{CB}, \chi(2,60)=15.29, \mathrm{p}=.000$, and TC groups, $\chi(2,46)=13.94, \mathrm{p}=.000$, which did not differ from each other. 
Externalizing Indices (Table 1)-As expected, given the use of the CPRS and CTRS to select participants, ratings on the DSM-IV Inattentive scale and Cognitive Problems/ Inattention subscales of the CPRS and CTRS for the PI and CB groups were highly and equivalently elevated (T-score means $>75$ ) and both exceeded those of the TC group. As also intended, children in the CB group were highly and significantly elevated compared to both PI and TC groups on the DSM-IV Hyperactivity-Impulsivity subscale. Scores on the SNAPIV, which was not used to select participants, yielded the same pattern - ie the two AD/HD subtypes were high and equivalent in number of inattention symptoms but well-separated with respect to number of hyperactive-impulsive symptoms, minimizing the likelihood that these cases of PI were simply subthreshold cases of CB (Milich et al., 2001).

Internalizing Indices-Multivariate analyses of scores from the CDI Parent and CDI Child were significant only for the CDI Parent, $\underline{\mathrm{F}}(6,122)=11.94, \underline{\mathrm{p}}=<.01$. Post-hoc univariate analyses revealed subtype differences only for Parent ratings on the Functional subscale that were higher for PI $(\underline{\mathrm{M}}=52.28, \underline{\mathrm{SD}}=9.22)$, compared to both the $\mathrm{CB}(\underline{\mathrm{M}}=48.00, \underline{\mathrm{SD}}=5.08)$ and $\mathrm{TC}(\underline{\mathrm{M}}=43.83, \underline{\mathrm{SD}}=6.82)$ groups, $\underline{\mathrm{F}}(2,63)=7.00, \underline{\mathrm{p}}<.01$.

Multivariate analyses of MASC scores were significant for Parent ratings, $\underline{\mathrm{F}}(14,110)=4.36$, $\underline{\mathrm{p}}<.001$, and Child ratings $\underline{\mathrm{F}}(14,130)=1.91, \mathrm{p}<.05$. Post hoc univariate analyses revealed that subtype differences were significant only for child-rated Harm Avoidance, $\underline{F}(2,71)=8.35$, $p$ $<.01$, such that children in the CB group rated themselves as having less Harm Avoidance $(\underline{\mathrm{M}}=50.82, \underline{\mathrm{SD}}=11.41)$ than did either the PI $(\underline{\mathrm{M}}=54.42, \underline{\mathrm{SD}}=8.43)$ or TC $(\underline{\mathrm{M}}=61.82$, $\underline{\mathrm{SD}}=4.05)$ groups. It is noteworthy that despite significant differences between groups on some factors, none of the CDI or MASC scores were clinically elevated (all mean T<65).

Given the general absence of differences between subtypes in internalizing symptoms, scores on the MASC and CDI were not used as covariates in the analyses of the neurocognitive tests.

\section{WISC-III and WIAT}

Groups were compared on the Processing Speed (PS) and Freedom from Distractibility (FD) Indices on the WISC-III. For each participant, the score on the PS Index was subtracted from score on the Verbal Comprehension scale. A criterion of discrepancy was established by selecting the score (15.8) which represents the difference that is significant at the .05 level for a 7-year old in the normative sample (Wechsler, 1991). (This is a conservative criterion since the criterion discrepancy score declines with increasing age.) The numbers of participants in the CB, PI, and TC groups, respectively, who met this discrepancy criterion were: $5(15 \%), 14$ $(54 \%)$ and $16(20 \%)[\chi(2,80)=12.02, \mathrm{p}=.002]$. Post hoc chi square, with one-tailed tests of significance, showed that the PI group exceeded both the CB $[\chi(1,60)=10.43, \mathrm{p}=.001]$ and TC groups $[\chi(1,46)=5.44, \mathrm{p}=.01]$, which did not differ from each other $[\chi(1,54)=.254, \mathrm{p}$ $=.61]$. Numbers of participants meeting the corresponding discrepancy criterion of 14.7 on the FD Index were: 12 (35\%), 12 (46\%) and 6 (30\%) for the CB, PI and TC groups, respectively $(\chi(2,80)=1.38, \mathrm{p}=.50)$., yielding no significant differences on this measure.

Results for Digit Span were examined separately for digits forward and digits backward; the latter is considered a measure of working memory. Means (raw scores, adjusted for IQ) for the PI, CB and TC groups were: 7.47, 7.92, and 7.75, respectively, for digits forward, and 4.33, 4.43 and 4. 91, respectively, for digits backward. Group differences were not significant.

MANCOVAs with IQ covariate yielded no differences between groups on grade-based standard scores in reading, math, and spelling. Univariate tests revealed a difference only on the spelling subtest, $\underline{\mathrm{F}}(2,76)=4.65, \mathrm{p}<.012$, due to significantly worse performance by both $\mathrm{AD} / \mathrm{HD}$ groups compared to the TC group. Means, adjusted for IQ, for the CB, PI, and TC groups were: $106.19(\underline{\mathrm{SE}}=2.11), 104.16(\underline{\mathrm{SE}}=2.33)$ and $115.07(\underline{\mathrm{SE}}=2.83)$, respectively. 
However, it is unlikely that a disability in spelling, in the absence of a disability in reading, would account for any differences in neurocognitive performance on the measures used in this study, therefore this score was not used as a co-variate in subsequent analyses.

\section{Neurocognitive Test Results}

Because this investigation was, in part, exploratory, both multivariate and univariate Fs are reported even where the multivariate $\mathrm{F}$ was not significant. The IQ co-variate was significant for the following (all $\mathrm{df}=1)$ : Stroop $(\underline{\mathrm{F}}=7.08, \mathrm{p}=.01)$; DAT $(\underline{\mathrm{F}}=4.80, \underline{\mathrm{p}}=.03)$; VLT $(\underline{\mathrm{F}}=$ $6.13, \underline{p}=.02) ; \operatorname{WCST}(\underline{\mathrm{F}}=4.37, \underline{\mathrm{p}}=.003)$; TOL $(\underline{\mathrm{F}}=3.71, \underline{\mathrm{p}}=.02)$; SRPT $(\underline{\mathrm{F}}=5.33, \underline{\mathrm{p}}=.02)$. For these and also for the TOL, Buschke, WSRT and CPT Checklist, for which Group effects differed with and without the co-variate, both sets of results are presented. For other tests, only results without the co-variate are presented. Results in Tables 2 and 3 are presented without the co-variate.

\section{Anterior vs. Posterior Attentional Systems}

Tests of Inhibitory Control-The MANOVA for CPT variables was not significant. However, exploratory ANOVAs yielded worse performance for CB than TC in RT-ISI Change and Beta, and worse performance for both AD/HD groups than the TC group in Hit RT SE. In the ANCOVAs only Hit RT SE reached or approached significance $(\mathrm{p}=.058)$.

The MANOVA for the CPT Checklist was significant due to higher frequency and severity scores for CB than both other groups. The MANCOVA was also significant, $\underline{\mathrm{F}}(4.102)=2.68$, $\mathrm{p}=.036$. Post-hoc test showed greater severity, but not frequency, for CB than PI and TC.

The ANOVA for the DAT was not significant. For the Stroop, the ANOVA yielded a significant effect of Group which was due to a lower T-score for the CB than the PI or TC groups. This group effect was reduced to a trend in the ANCOVA.

Tests of Working Memory-Separate MANOVAs for the WCST and TOL were each significant for Group. Exploratory univariate analyses for the WCST showed worse performance for the CB group than both other groups with respect to Categories Completed and Total Errors; however, these effects were no longer significant after co-varying IQ. On the TOL, the CB group had significantly more Total Moves and Total Rule Violations than the other groups. Both $\mathrm{AD} / \mathrm{HD}$ groups had longer TOL Execution Times than TC. When analyzed by MANCOVA, the Group effect remained significant, $\underline{\mathrm{F}}(6,126)=2.80, \underline{\mathrm{p}}=.014)$. Post-hoc univariate tests revealed a group effect for TOL Rule Violations (CB group worse than PI).

Posner Task-A preliminary analysis showed no significant effects of Visual Field or Block, so analysis was collapsed over these factors. Mean RTs were entered into a repeated measures ANOVA having one factor of Group, one factor of Cue with 4 levels (valid, invalid, double, and null) and one factor of Delay with 2 levels $(200 \mathrm{msec}$ and $800 \mathrm{msec})$. The main effect of Cue was significant, $\underline{\mathrm{F}}(3,75)=173.12, \underline{\mathrm{p}}=.000$, as was the main effect of Delay, $\underline{\mathrm{F}}(1,77)=$ $77.32, \underline{p}=.000$ and the interaction between Cue and Delay $\underline{F}(3,75)=7.93, \underline{p}=.014$. However, effects involving Group were not significant.

Post-hoc tests indicated that the task generated the expected cue patterns: valid cues were associated with the shortest RTs ( $\underline{\mathrm{SE}}$ valid vs. null cue $=3.74, \mathrm{p}=.000$ ) and invalid cues with the longest RTs. Double cues exerted partial benefit compared to the null cue $(\underline{\mathrm{SE}}=4.772, \mathrm{p}$ $=.000$ ), most likely through an alerting mechanism. Post-hoc tests yielded trends for quadratic and cubic effects of Cue with a non-significant linear effect. The benefits of a valid cue were strengthened at the longer delay interval, accounting for the significant Cue X Delay interaction. 
The analyses were repeated to examine error frequency. In the ANOVA there was a significant effect of Group $(\mathrm{F}=3.17, \mathrm{df}=2, \mathrm{p}=.047)$ such that the $\mathrm{CB}$ group had significantly more errors than the other groups. This finding allows the possibility that RT was equivalent across groups because children with CB employed a speed-accuracy tradeoff favoring speed. However, this effect was no longer significant when IQ was co-varied.

\section{Activation vs. Arousal}

Sternberg Task-Analysis of mean RT was conducted via repeated-measures ANOVA with one factor of Group and one factor of Memory Set (1 item or 4 items). The effect of Memory Set was significant, such that RT, as expected, was longer for the larger set, $\underline{F}=(1,73)=6.86$, $\mathrm{p}=.011$. However, neither the effect of Group, $\underline{\mathrm{F}}(2,73)=1.02, \mathrm{p}=.39)$ nor the interaction between Group and Memory Set, $\underline{\mathrm{F}}(2,73)=1.13, \mathrm{p}=.342$, was significant. When IQ was covaried, the effect of Memory Set was no longer significant. Analysis of incorrect responses and failures to respond yielded no significant differences across groups.

SRPT-Median RTs were analyzed using repeated measures ANOVA with one factor of Group, one factor of Stimulus type (hard or easy), one factor of Response type (hard or easy), and one factor of block with 2 levels. Effects of Stimulus type, $\underline{F}(1,71)=141.91, p=.000$, and Response type, $\underline{\mathrm{F}}(1,71)=174.93 .79, \underline{\mathrm{p}}=.000$, were highly significant such that the more difficult stimulus or response was associated, as expected, with longer median RTs. The hard response had a greater effect in increasing RT when paired with the hard stimulus than with the easy stimulus, reflected in a significant interaction between Stimulus and Response, $\underline{\mathrm{F}}(1,71)$ $=5.12, \underline{p}=.026$. There was a trend for an interaction between Response and Group, $\underline{\mathrm{F}}(2,71)$ $=2.38, \mathrm{p}=.100$, such that the hard Response condition slowed the RT of the PI and CB Groups, which were indistinguishable, more than that of the TC Group. Other main effects and interactions were not significant. In the ANCOVA, the effect of Response type remained significant; however, the effect of Stimulus type fell just short of significance $(\mathrm{p}=.054)$. Neither the interaction between Stimulus and Group, nor the interaction between Response and Group, were significant.

Analysis of number correct (which ranged between 21.5 and $22.4(\underline{\mathrm{SE}}=.34$ to .42$)$ across groups revealed no significant main effects or interactions.

WSRT-Repeated measures ANOVA of median RT scores was performed with one factor of Group with 3 levels and one factor of warning Interval with 3 levels (1000, 4000, and 8000 $\mathrm{msec}$ ). When analyzed without the IQ covariate, the main effect of Interval was highly significant $(\underline{F}(2,76)=29.25, \underline{p}=.000)$; however, effects involving Group were not significant. Post hoc analysis showed that the median RT following the shortest warning was longer than RT's to the other two intervals, which did not differ from each other. When analyzed by ANCOVA none of the effects were significant.

\section{Memory Tests}

For the Buschke, the MANOVA yielded a significant effect of Group. Post-hoc univariate analyses indicated that the CB group performed worse than TC on Total Recall, Long-term Storage, Long-term Retrieval, and worse than both other groups on Delayed Recall. The MANCOVA was not significant, however. ANCOVAs showed only significantly worse Delayed Recall for the CB than for the other groups. There were no significant findings for the VLT.

\section{Re-analysis by Latent Class}

Re-analysis of the data following re-assignment to groups based on LCA criteria yielded only minor changes in the results. ${ }^{1}$ 


\section{Discussion}

On the neurocognitive battery, before controlling for IQ, children with CB performed more poorly than the TC and PI groups with respect to: observational measures of motor impulsivity while performing cognitive tasks (CPT and TOL); cognitive inhibitory control (Stroop Interference); visual-spatial working memory and planning (Total Moves on the TOL); and memory (Buschke delayed recall). In addition, exploratory analyses revealed marginally significant increases for CB compared to the TC group in set-shifting (WCST categories completed) and attentiveness (CPT d prime and variability of RT).

Children with PI were indistinguishable from typical comparisons on these measures, with the exception of execution time on the TOL and variability of Hit RT on the CPT, on which they were as slow and as variable as children with CB. After controlling for group differences in IQ, remaining subtype differences were primarily on the observational measures of impulsive behavior, with the CB group showing greater impulsivity than both the PI and TC groups. In addition, the PI group had slower processing speed than CB and TC on a commonly used index from the WISC-III. After controlling for IQ, there were no group differences in verbal or nonverbal working memory or planning (Digit Span, WCST, TOL). Both AD/HD groups showed marginally increased variability in RT, compared to typical comparisons, on the CPT. Thus, the data provide minimal support for subtype differences in executive functions mediated by the AAS. Differences in memory storage and retrieval functions were limited to the CB group on delayed recall (Buschke).

Whether analyzed with or without the IQ co-variate, there was no support in the data for hypothesized differences between subtypes in the functioning of the PAS, nor in involvement of arousal vs. activation processes.

\section{Differences between Subtypes}

The current results are similar to those which have most consistently differentiated the CB and PI subtypes in prior studies: (a) greater difficulty with inhibitory control in the CB type, as reflected on the SSRT (Nigg et al., 2002) or CPT (Hinshaw et al., 2002; Huang-Pollock, Nigg, and Halperin, 2006) and (b) a greater deficit in processing speed on visual-motor or visual search tasks in the PI type (Chhabildas, Pennington, \& Willcutt, 2001; Nigg et al., 2002).

It is of interest that in the current study the only difference which emerged among groups across six key CPT indices after co-varying IQ was a marginally significant finding (before correcting for multiple tests) for variability of RT to hits, such that both $\mathrm{AD} / \mathrm{HD}$ groups were more variable than comparisons. This result is consistent with previous work that showed that, among CPT indices, RT variability was most strongly related to AD/HD symptomatology (Epstein, Erkanli, Conners, Costello, \& Angold, 2003).

The Posner Task did not yield the predicted group differences in RT or errors as a function of cue validity, lending no support for the hypothesis of reduced efficiency in PI of stimulus disengagement process mediated by the PAS. Furthermore, RT data provided no evidence of differences in alerting or arousal processes. These findings are similar to those reported for CB

\footnotetext{
${ }^{1}$ Latent class analysis (LCA) is a cluster-analytic method that has been used to examine the extent to which the 18 DSM-IV symptoms of $\mathrm{AD} / \mathrm{HD}$ cluster together in large, population-based samples. Applied to parent ratings, LCA yielded eight latent classes, including three that overlap substantially, but not completely, with the three DSM-IV subtypes (Hudziak et al., 1998). Subtype-specific concordance in twin data suggests that LCA may afford a more genetically valid classification of AD/HD subtypes than do DSM-IV criteria (Rasmussen et al., 2004). Participants in the current study were re-assigned to groups based on application of latent class criteria to parent symptom ratings on the SNAP-IV (Neuman et al., 1999). Twenty-four of 34 (71\%) subjects in the CB group met criteria for the "severe combined" latent class, 21 of $26(81 \%)$ of PI subjects met criteria for the "severe inattentive" latent class; and 19 subjects were retained in the TC group.
} 
(Huang-Pollock \& Nigg, 2003) and, very recently, for the PI subtype as well (Huang-Pollock et al., 2006).

Three tests in the current battery were utilized to test hypotheses that the PI subtype has greater difficulty in the stimulus encoding stage of information processing whereas the CB subtype is compromised with respect to response organization and output processes. The Sternberg, SRPT, and WSRT successfully manipulated memory load, stimulus/response difficulty and warning interval, respectively, yielding the expected differences in RT for these variables across groups. However, there was no support for the predicted subtype differences.

\section{Differences between CB and Controls}

Not only did these results largely fail to support the hypothesized subtype differences in neurocognitive processing, they also failed to replicate previously reported differences between CB and TC groups on some measures of executive function, including the WCST and TOL (Willcutt, Doyle, Nigg, Faraone, \& Pennington, 2005). However, closer inspection of the literature reveals that some studies purporting to find differences failed to covary for IQ, that few studies systematically excluded children with learning disabilities, and that even fewer have excluded children with comorbid psychiatric conditions. For example, a meta-analysis of 25 studies utilizing the WCST found a moderate weighted mean effect size for differences between AD/HD and comparisons (Romine et al., 2004). However, children with reading disabilities, developmental language disorder or anxiety disorders also performed more poorly than controls, suggesting that different results across studies may be attributable to varying comorbidities within the AD/HD samples. Similarly, two of the three studies reporting significant differences between AD/HD and control groups on the TOL in a recent meta-analysis (Willcutt et al., 2005) did not covary for possible IQ differences (Culbertson \& Zillmer, 1998; Kempton et al., 1999). In addition, two more recent studies, not included in the meta-analysis, found that the group difference in performance on the TOL was no longer significant after controlling for the effects of age, IQ, and performance on non-EF tasks (Geurts et al., 2004; Scheres et al., 2004).

The lack of difference between AD/HD and TC groups on the DAT in this study is perplexing, given robust differences in a prior study employing the identical measure (Solanto et al., 2001). It is of interest that, in this study, compared to the previous, the children with AD/HD were slightly less delay-averse and the TC group substantially more delay-averse, resulting in a converging of their mean scores. Yet children in the current comparison group were more likely to be high-functioning than those in the previous one. In this study the DAT was administered as the first test in the battery, whereas previously it was given after a more lengthy and effortful task; however, this difference might have been expected to make the children in the current study generally less impatient and less delay-averse. Thus we lack a clear explanation for this finding.

\section{Limitations}

Sample sizes in the current study may not have provided sufficient power to find significant differences between groups. However, power was $80 \%$ to detect a small to medium effect size of .35, which corresponds to an explained variance of about 3\%. Furthermore, the actual effect sizes associated with the non-significant results of this study were less than .10, indicating the absence of meaningful group differences for those measures.

Corroborating other studies (Bauermeister et al., 2005; McBurnett \& Pfiffner, 2001), a substantial proportion (50\%) of PI cases met criteria for SCT; however, the subgroups were not large enough to compare statistically. Future studies should include subsamples of PI with 
and without SCT of sufficient size to detect potential differences in neurocognition, although prior research with girls has not been promising in this regard (Hinshaw et al., 2002).

\section{Conclusions}

In summary, these current results indicate that the PI and CB groups are best differentiated by ratings, observations and laboratory tests of cognitive tempo and behavioral impulsivity. In this, as in previous studies, neurocognitive tests were not helpful in elucidating the neurobiological substrates of these differences. One conclusion from the current findings is that whereas the AD/HD PI and CB subtypes differ in apparent behavioral phenotype, they do not differ in endophenotype but rather represent varying manifestations of the same underlying disorder. Alternatively, genetic approaches may be more successful in identifying differences between subtypes in neuropathology, as suggested by differences in frequency of DAT1 allelles (Waldman \& Gizer, 2006). Another possibility is that the DSM-IV criteria as currently formulated do not distinguish valid subtypes. Reclassifying participants according to LCA criteria in the current study, however, did not change the pattern of results.

The lack of differences between $\mathrm{AD} / \mathrm{HD}$ and TC groups on most measures after co-varying for IQ calls into question the importance of executive dysfunction in $\mathrm{AD} / \mathrm{HD}$, as have recent studies and reviews challenging the universality (Nigg, Willcutt, Doyle, \& Sonuga-Barke, 2005; Sonuga-Barke, 2005) and specificity (Doyle, Biederman, Seidman, Weber, \& Faraone, 2000; Sergeant, Geurts, \& Oosterlaan, 2002) of executive dysfunction in any type of AD/HD.

\section{Acknowledgements}

This work was supported by the following grants to the first author from the National Institute of Child Health and Human Development: HD36688 and HD37803. We extend thanks to: Jim Swanson, Ph.D. and Tim Wigal, Ph.D. for providing the software and support for the Posner and Sternberg tasks; Eliu Turkel, Ph.D. for consultation on data extraction from MEL; and Jeffrey Halperin, Ph.D. for comments on the manuscript. We appreciate the assistance of Gina McSheffrey and Evelyn Velez with data compilation and entry. We extend our thanks to: Mary Cary Ambler, Learning Specialist at the Convent of the Sacred Heart, Greenwich, CT; Don Kramer, Principal of Our Lady of Good Counsel School, N.Y., N.Y.; and Sr. Josephine Cioffi, Principal of St. Ann Parish Elementary School, N.Y., N.Y. for their support of the project. We acknowledge with gratitude the contribution of all the children and parents who participated.

\section{References}

American Psychiatric Association. Diagnostic and statistical manual of mental disorders. 3. Washington, D.C.: Author; 1980.

American Psychiatric Association. Diagnostic and statistical manual of mental disorders. 4. Washington, D.C.: Author; 1994.

Applegate B, Lahey BB, Hart EL, Biederman J, Hynd GW, Barkley RA, Ollendick T, Frick PJ, Greenhill L, McBurnett K, Newcorn JH, Kerdyk L, Garfinkel B, Waldman I, Shaffer D. Validity of the age-ofonset criterion for ADHD: A report from the DSM-IV field trials. Journal of the American Academy of Child and Adolescent Psychiatry 1997;36:1211-1221. [PubMed: 9291722]

Arnsten, AFT. Dopaminergic and noradrenergic influences on cognitive functions mediated by prefrontal cortex. In: Solanto, MV.; Arnsten, AFT.; Castellanos, FX., editors. Stimulant Drugs and ADHD: basic and clinical neuroscience. New York: Oxford; 2001. p. 185-208.

Baker SC, Rogers RD, Owen AM, Frith CD, Dolan RJ, Frackowiak RSJ, Robbins TW. Neural systems engaged by planning: a PET study of the Tower of London task. Neuropsychologia 1996;34(6):515526. [PubMed: 8736565]

Barkley RA. Behavioral inhibition, sustained attention, and executive functions: Constructing a unifying theory of ADHD. Psychological Bulletin 1997;121:65-94. [PubMed: 9000892]

Barkley RA, DuPaul GJ, McMurray MB. Attention deficit disorder with and without hyperactivity: Clinical response to three dose levels of methylphenidate. Pediatrics 1991;87:519-531. [PubMed: 2011430] 
Bauermeister JJ, Matos M, Reina G, Salas CC, Martinez JV, Cumba E, Barkley RA. Comparison of the DSM-IV combined and inattentive types of ADHD in a school-based sample of Latino/Hispanic children. Journal of Child Psychology and Psychiatry 2005;46(2):166-179. [PubMed: 15679525]

Berg EA. A simple objective technique for measuring flexibility in thinking. Journal of General Psychology 1948;39:15-22.

Berman KF, Ostrem JL, Randolph C, Gold J, Goldberg TE, Coppola R, Carson RE, Herscovitch P, Weinberger DR. Physiological activation of a cortical network during performance of the Wisconsin Card Sorting Test: A positron emission tomography study. Neuropsychologia 1995;33:1027-1046. [PubMed: 8524452]

Buschke H, Fuld PA. Evaluating storage, retention, and retrieval in disordered memory and learning. Neurology 1974;24:1019-1025. [PubMed: 4473151]

Bush G, Whalen PJ, Rosen BR, Jenike MA, McInerney SC, Rauch SL. The counting Stroop: an interference task specialized for functional neuroimaging - validation study with functional MRI. Human Brain Mapping 1998;6:270-282. [PubMed: 9704265]

Castellanos RX, Tannock R. Neuroscience of attention-deficit/hyperactivity disorder: the search for endophenotypes. Nature Reviews Neuroscience 2002:617-628.

Chhabildas N, Pennington B, Willcutt EG. A comparison of the neuropsychological profiles of the DSMIV subtypes of ADHD. Journal of Abnormal Child Psychology 2001;29:529-540. [PubMed: 11761286]

Cohen, J. Statistical power analysis for the behavioral sciences. 2. Hillsdale, NJ: Laurence Erlbaum; 1988.

Conners, CK. The Conners' Continuous Performance Test. Toronto: Multi-Health Systems; 1994.

Conners CK, Sitarenios G, Parker J, Epstein JN. Revision and restandardization of the Conners' Teacher Rating Scale (CTRS-R): Factor structure, reliability, and criterion validity. Journal of Abnormal Child Psychology 1998a;26:279-291. [PubMed: 9700520]

Conners CK, Sitarenios G, Parker JDA, Epstein JN. The revised Conners' Parent Rating Scale (CPRSR): Factor structure, reliability, and criterion validity. Journal of Abnormal Child Psychology 1998b; 25:257-268.

Culbertson WC, Zillmer EA. The Tower of London (DX): a standardized approach to assessing executive functioning in children. Archives of Clinical Neuropsychology 1998;13:285-301. [PubMed: 14590643]

Culbertson, WC.; Zillmer, EA. Tower of London-Drexel University (TOLDX) Technical Manual. first. Tonawanda N.Y.: Multi-Health Systems, Inc; 2001.

Doyle A, Biederman J, Seidman L, Weber W, Faraone S. Diagnostic efficiency of neuropsychological test scores for disciminating boys with and without attention deficit hyperactivity disorder. Journal of Consulting and Clinical Psychology 2000;68:477-488. [PubMed: 10883564]

Eiraldi RB, Power TJ, Nezu CM. Patterns of comorbidity associated with subtypes of attention-deficit/ hyperactivity disorder among 6-to 12-year-old children. Journal of the American Academy of Child and Adolescent Psychiatry 1997;36:503-514. [PubMed: 9100425]

Epstein JN, Erkanli A, Conners CK, Klaric J, Costello JE, Angold E. Relations between Continuous Performance Test performance measures and ADHD behaviors. Journal of Abnormal Child Psychology 2003;31:543-554. [PubMed: 14561061]

Gaub M, Carlson C. Gender differences in ADHD: A meta-analysis and critical review. Journal of the American Academy of Child and Adolescent Psychiatry 1997a;36:1035-1045.

Gaub M, Carlson CL. Behavioral characteristics of DSM-IV ADHD subtypes in a school-based population. Journal of Abnormal Child Psychology 1997b;25:103-111. [PubMed: 9109027]

Geurts HM, Verte S, Oosterlaan J, Roeyers H, Sergeant JA. ADHD subtypes: do they differ in their executive functioning profile? Archives of Clinical Neuropsychology 2004;20(4):457-477. [PubMed: 15896560]

Golden, CJ. The Stroop Color and Word Test: A Manual for Clinical Uses. Chicago, IL: Stoelting Co; 1978.

Gomez R, Harvey J, Quick C, Scharer I, Harris G. DSM-IV AD/HD: Confirmatory factor models, prevalence, and gender and age differences based on parent and teacher ratings of Australian primary school children. Journal of Child Psychology and Psychiatry 1999;40:265-274. [PubMed: 10188709] 
Hartman CA, Willcutt EG, Rhee SH, Pennington BF. The relation between sluggish cognitive tempo and DSM-IV ADHD. Journal of Abnormal Child Psychology 2004;32(5):491-503. [PubMed: 15500029]

Heaton, RK. Wisconsin Card Sorting Test Manual. Odessa, Fl 33556: Psychological Assessment Resources, Inc; 1981.

Heaton, RK. Wisconsin Card Sorting Test (Version 4-Research Edition) [Computer software]. Lutz, FL: Psychological Assessment Resources, Inc; 2003.

Hinshaw SP, Carte ET, Sami N, Treuting JJ, Zupan BA. Preadolescent girls with attention-deficit/ hyperactivity disorder: II. Neuropsychological performance in relation to subtypes and individual classification. Journal of Consulting and Clinical Psychology 2002;70:1099-1111. [PubMed: 12362960]

Houghton S, Douglas G, West J, Whiting K, Wall M, Langsford S, Powell L, Carroll A. Differential patterns of executive function in children with attention-deficit hyperactivity disorder according to gender and subtype. Journal of Child Neurology 1999;14:801-805. [PubMed: 10614567]

Huang-Pollock CL, Nigg JT. Searching for the deficit in attention deficit/hyperactivity disorder: The case of visuospatial orienting. Clinical Psychology Review 2003;23:801-830. [PubMed: 14529699]

Huang-Pollock CL, Nigg JT, Halperin JM. Single dissociation findings of ADHD deficits in vigilance but not anterior or posterior attention systems. Neuropsychology 2006;20(4):420-429. [PubMed: 16846260]

Hudziak JJ, Heath AC, Madden PF, Reich W, Bucholz KK, Slutske W, Bierut LJ, Neuman RJ, Todd RD. Latent class and factor analysis of DSM-IV ADHD: a twin study of female adolescents. Journal of the American Academy of Child and Adolescent Psychiatry 1998;37:848-857. [PubMed: 9695447]

Ishihara, S. Ishihara Test for Color Blindness. 1960 [2006, July 13]. Available: http://www.toledo-bend.com/colorblind/links.html

Kaplan, E.; Goodglass, H.; Weintraub, S. The Boston Naming Test. Philadelphia, PA: Lea \& Febiger; 1983.

Kempton S, Vance A, Maruff P, Luk E, Costin J, Pantelis C. Executive function and attention deficit hyperactivity disorder: stimulant medication and better executive function performance in children. Psychological Medicine 1999;29:527-538. [PubMed: 10405075]

Klorman R, Hazel-Fernandez LA, Shaywitz SE, Fletcher JM, Marchione KE, Holahan JM, Stuebing KK, Shaywitz BA. Executive functioning deficits in attention-deficit/hyperactivity disorder are independent of oppositional defiant or reading disorder. Journal of the American Academy of Child and Adolescent Psychiatry 1999;38:1148-1155. [PubMed: 10504814]

Kovacs, M. Children's Depression Inventory. North Tonawanda, NY: Multi-Health Systems, Inc; 1992.

Lahey BB. Should the combined and predominantly inattentive types of ADHD be considered distinct and unrelated disorders? Not now, at least. Clinical Psychology: Science and Practice 2001;8:494497.

Lahey BB, Pelham WE, Stein MA, Loney J, Trapani C, Nugent K, et al. Validity of DSM-IV attentiondeficit/hyperactivity disorder for younger children. Journal of the American Academy of Child and Adolescent Psychiatry 1998;37:695-702. [PubMed: 9666624]

Lahey BB, WE P, Schaughency EA, Atkins MS, Murphy HA, Hynd G, Russo M, Hartdagen S, LorysVernon A. Dimensions and types of attention deficit disorder. Journal of the American Academy of the Child and Adolescent Psychiatry 1988;27:330-335.

Maedgen JW, Carlson CL. Social functioning and emotional regulation in the attention deficit hyperactivity disorder subtypes. Journal of Clinical Child Psychology 2000;29:30-42. [PubMed: 10693030]

March J, Parker J, Sullivan K, Stallings P, Conners CK. The Multidimensional Anxiety Scale for Children (MASC): Factor structure, reliability, and validity. Journal of the American Academy of Child and Adolescent Psychiatry 1997;36:554-565. [PubMed: 9100431]

McBurnett K, Pfiffner LJ. Symptom properties as a function of ADHD type: An argument for continued study of sluggish cognitive tempo. Journal of Abnormal Child Psychology 2001;29:207-213. [PubMed: 11411783]

McBurnett K, Pfiffner LJ, Willcutt E, Tamm L, Lerner M, Ottolini YL, Furman MB. Experimental crossvalidation of DSM-IV types of attention-deficit/hyperactivity disorder. Journal of the American Academy of Child and Adolescent Psychiatry 1999;38:17-24. [PubMed: 9893412] 
Milich R, Balentine A, Lynam D. ADHD Combined Type and ADHD Predominantly Inattentive Type are distinct and unrelated disorders. Clinical Psychology: Science \& Practice 2001;8:463-488.

Neuman RJ, Todd RD, Heath AC, Reich W, Hudziak JJ, Bucholz KK, Madden PAF, Begleiter H, Porjesz B, Kuperman S, Hesselbrock V, Reich T. Evaluation of ADHD typology in three contrasting samples: A latent class approach. Journal of the American Academy of Child and Adolescent Psychiatry 1999;38:25-33. [PubMed: 9893413]

Nigg JT. Neuropsychologic theory and findings in attention-deficit/hyperactivity disorder: the state of the field and salient challenges for the coming decade. Biological Psychiatry 2005;57(11):14241435. [PubMed: 15950017]

Nigg JT, Blaskey LG, Huang-Pollock CL, Rappley MD. Neuropsychological executive functions and DSM-IV subtypes. Journal of the American Academy of Child and Adolescent Psychiatry 2002;41:59-66. [PubMed: 11800208]

Nigg JT, Willcutt EG, Doyle AE, Sonuga-Barke JS. Causal heterogeneity in Attention-Deficit/ Hyperactivity Disorder: Do we need neuropsychologically impaired subtypes? Biological Psychiatry 2005;57(11):1224-1230. [PubMed: 15949992]

Pelham WE Jr, Gnagy EM, Greenslade KE, Milich R. Teacher ratings of DSM-III-R symptoms for the disruptive behavior disorders. Journal of the American Academy of Child and Adolescent Psychiatry 1992;31:210-218. [PubMed: 1564021]

Pope, S.; Solanto, MV.; Tryon, WW.; Stepak, B. Social skills in subtypes of children with AD/HD; Paper presented at the American Psychological Association; Wash, D.C. 2005.

Posner M, Petersen SE. The attention system of the brain. Annual Review of Neuroscience 1990;13:3542.

Posner, M.; Raichle, M. Images of mind. New York: Scientific American Library; 1994. Networks of Attention; p. 152-179.

Power TJ, Costigan TE, Eiraldi RB, Leff SS. Variations in anxiety and depression as a function of ADHD subtypes defined by DSM-IV: do subtype differences exist or not? Journal of Abnormal Child Psychology 2004;32(1):27-37. [PubMed: 14998109]

Rasmussen ER, Neuman RJ, Heath AC, Levy F, Hay DA, Todd RD. Familial clustering of latent class and DSM-IV defined attention-deficit/hyperactivity disorder (ADHD) subtypes. Journal of Child Psychology and Psychiatry 2004;45:589-598. [PubMed: 15055377]

Romine CB, Lee DL, Wolfe ME, Homack S, George C, Riccio C. Wisconsin Card Sorting Test with children: a meta-analytic study of sensitivity and specificity. Archives of Clinical Neuropsychology 2004;19(8):1027-1041. [PubMed: 15533695]

Sanders AV. Towards a model of stress and human performance. Acta Psychologica 1983;53:61-97. [PubMed: 6869047]

Schachar R, Tannock R, Marriott M, Logan G. Deficient inhibitory control in attention deficit hyperactivity disorder. Journal of Abnormal Child Psychology 1995;23:411-437. [PubMed: 7560554]

Scheres A, Oosterlaan J, Geurts H, Morein-Zamir S, Meiran N, Schut H, Vlasveld L, Sergeant JA. Executive functioning in boys with ADHD: primarily an inhibition deficit? Archives of Clinical Neuropsychology 2004;19(4):569-594. [PubMed: 15163457]

Schneider, W. Micro Experimental Laboratory. Pittsburgh, PA: Psychology Software Tools, Inc; 1990.

Sergeant JA. Modeling Attention-Deficit/Hyperactivity Disorder: A critical appraisal of the cognitiveenergetic model. Biological Psychiatry 2005;57(11):1248-1255. [PubMed: 15949995]

Sergeant JA, Geurts H, Oosterlaan J. How specific is a deficit of executive functioning for AttentionDeficit/Hyperactivity Disodrer. Behavioural Brain Research 2002;130:3-28. [PubMed: 11864714]

Sergeant JA, Scholten CA. A stages-of-information approach to hyperactivity. Journal of Child Psychology and Psychiatry 1983;24:49-60. [PubMed: 6826676]

Shaffer D, Fisher P, Dulcan M, Davies M, Piacentini J, Schwab-Stone M, Lahey BB, Bourdon K, Jensen PS, Bird HR, Canino G, Regier D. The NIMH Diagnostic Interview Schedule for Children Version 2.3 (DISC-2.3): Description, acceptability, prevalence rates, and performance in the MECA study. Journal of the American Academy of Child and Adolescent Psychiatry 1996;35:865-877. [PubMed: 8768346] 
Sheslow, D.; Adams, W. Wide Range Assessment of Memory and Learning. Wilmington, DE: Jastak Associates Inc; 1990.

Solanto MV, Abikoff H, Sonuga-Barke E, Schachar R, Logan G, Wigal T, Hechtman L, Hinshaw S, Pollock S, Turkel E. The ecological validity of delay aversion and response inhibition as measures of impulsivity in AD/HD: A supplement to the NIMH Multi-Modal Treatment Study of AD/HD. Journal of Abnormal Child Psychology 2001;29:215-228. [PubMed: 11411784]

Solanto MV, Wender EH, Bartell SS. Effects of methylphenidate and behavioral contingencies on vigilance in AD/HD: A test of the reward dysfunction hypothesis. Journal of Child and Adolescent Psychopharmacology 1997;7:123-136. [PubMed: 9334897]

Sonuga-Barke EJS. Causal models of Attention-Deficit/Hyperactivity Disorder: From common simple deficits to multiple developmental pathways. Biological Psychiatry 2005;57:1231-1238. [PubMed: 15949993]

Sonuga-Barke EJS, Taylor E, Sembi S, Smith J. Hyperactivity and delay aversion - I. The effect of delay on choice. Journal of Child Psychology and Psychiatry 1992;33:387-398. [PubMed: 1564081]

Spreen, O.; Strauss, E. Bushke Selective Reminding Test (SRT). Oxford; 1998. A compendium of neuropsychological tests; p. 282-295.

Sternberg S. Discovery of processing stages: Extensions of Donders' method. Acta Psychologica 1969;8:276-315.

Tucker DM, Williamson PA. Asymmetric neural control systems in human self-regulation. Psychological Review 1984;91:185-215. [PubMed: 6152836]

van Mourik R, Oosterlaan J, Sergeant JA. The Stroop revisited: a meta-analysis of interference control in AD/HD. The Journal of Child Psychology and Psychiatry 2005;46:150-165.

Waldman ID, Gizer IR. The genetics of attention deficit hyperactivity disorder. Clinical Psychology Review 2006;26(4):396-432. [PubMed: 16513236]

Wechsler, D. Manual for the Wechsler Intelligence Scale for Children - Third Edition. San Antonio, TX: The Psychological Corporation; 1991.

Wechsler, D. The Manual for the Wechsler Individual Achievement Test. San Antonio, TX: The Psychological Corporation; 1992.

Werry JS, Elkind GS, Reeves JS. Attention deficit, conduct, oppositional, and anxiety disorders in children: III. Laboratory differences. Journal of Abnormal Child Psychology 1987;15:409-428. [PubMed: 3668087]

Wig, EH.; Secord, W. The Test of Language Competence - Expanded Edition. San Antonio, Texas: The Psychological Corporation; 1989.

Willcutt EG, Doyle AE, Nigg JT, Faraone SV, Pennington BF. Validity of the executive function theory of Attention-Deficit/Hyperactivity Disorder: A meta-analytic review. Biological Psychiatry 2005;57:1336-1346. [PubMed: 15950006]

Willcutt EG, Pennington BF, Chhabildas NA, Friedman MC, Alexander J. Psychiatric comorbidity associated with DSM-IV ADHD in a nonreferred sample of twins. Journal of the American Academy of Child and Adolescent Psychiatry 1999;38:1355-1362. [PubMed: 10560221]

Wolraich ML, Hannah JN, Pinnock TY, Baumgaertel A, Brown J. Comparison of diagnostic criteria for attention-deficit hyperactivity disorder in a county-wide sample. Journal of the American Academy of Child and Adolescent Psychiatry 1996;35:319-324. [PubMed: 8714320] 


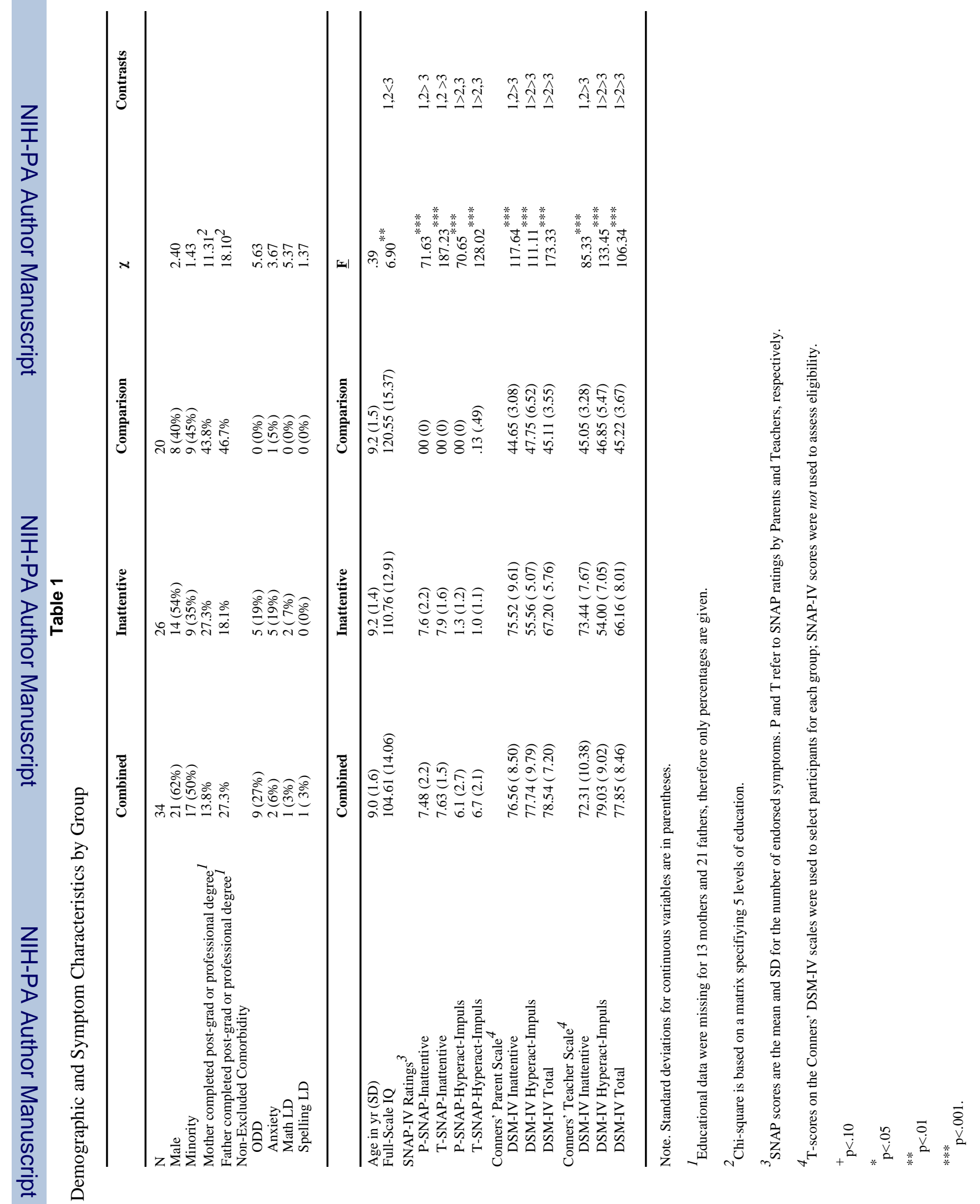




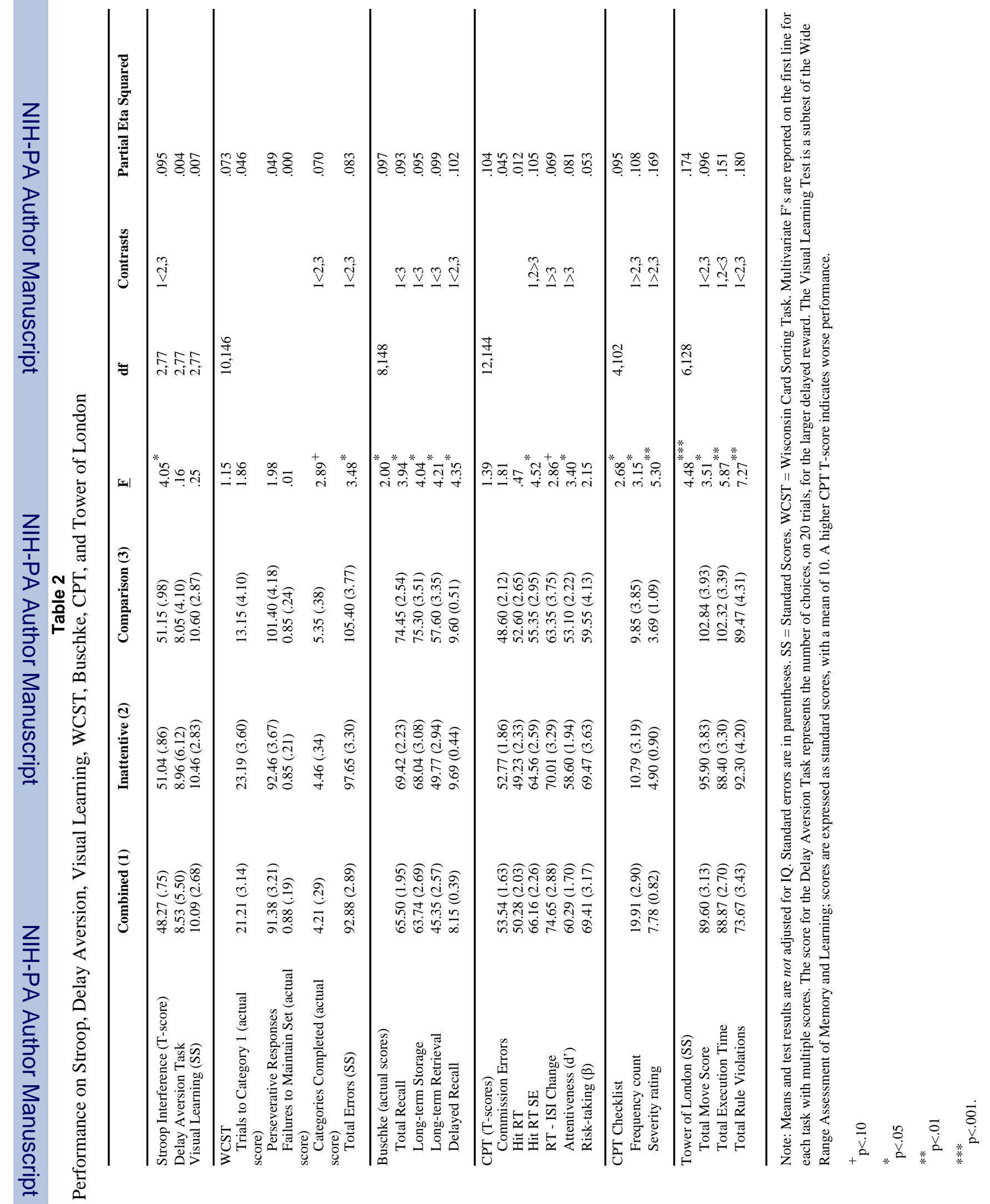




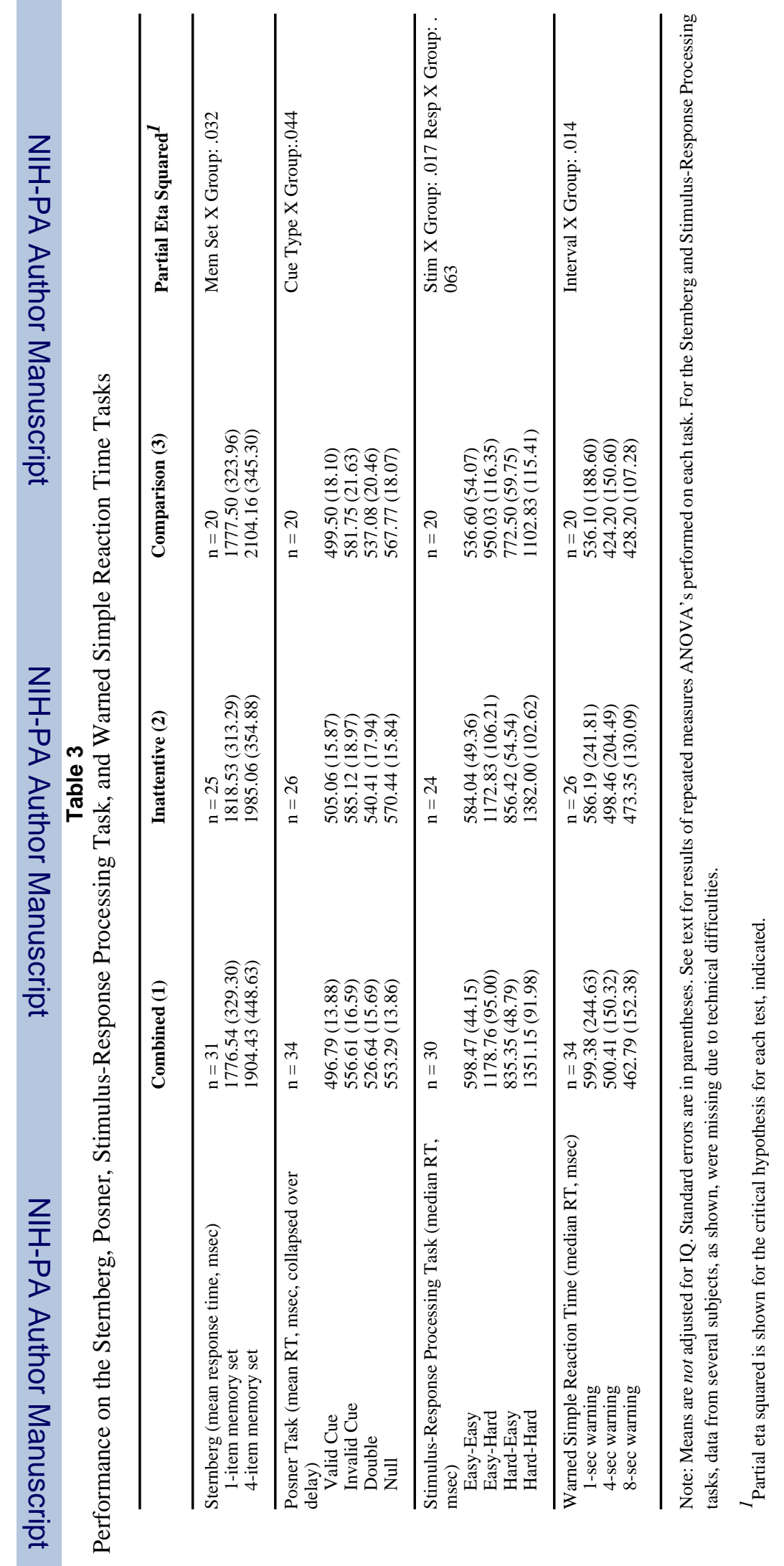

